\title{
Contextos sintáticos e desvios de concordância nominal em português língua estrangeira
}

\author{
Diocleciano Nhatuve*
}

\begin{abstract}
Resumo
O objetivo deste estudo é identificar os contextos e as funções sintáticas em que ocorrem índices elevados de concordância nominal desviante e os aspectos psicocognitivos, sociais e linguísticos que favorecem os comportamentos de aprendentes de português língua estrangeira (PLE). O estudo é conduzido com base nos princípios de primazia do significado no processamento do input e de aprendizagem tardia de línguas. A base empírica é constituída por estruturas sintáticas desviantes de 10 grupos de aprendentes de português em universidades africanas, asiáticas e europeias. A análise qualitativa e quantitativa indica que, na maioria dos grupos, os desvios ocorrem em sintagmas nominais com as funções de objeto direto, em complementos de preposições e em predicativo de sujeito. Entretanto, o comportamento diferente de aprendentes coreanos e alemães leva-nos a considerar, entre outros aspectos, a ordem das palavras de cada língua como um dos factores determinantes para a ocorrência de desvios em determinados contextos.
\end{abstract}

Palavras-chave: Concordância nominal. Contextos e funções sintáticas. Aprendentes de PLE africanos, asiáticos e europeus. Tendências.

\footnotetext{
* Universidade do Zimbabwe (UZ). Doutorado em Linguística do Português (Universidade de Coimbra). Mestre em Ciências da Linguagem e Comunicação (Universidade de Évora). Licenciado em Ensino de Português (Universidade Eduardo Mondlane). Leitor de Português na Universidade do Zimbabwe. Orcid: http://orcid.org/0000-0003-4749-1348.
} 


\title{
Syntactic contexts and non-target nominal agreement in Portuguese as foreign language
}

\begin{abstract}
This article aims to identify syntactic contexts and elements in which many cases of non-target nominal agreement occur. It also aims to identify psychocognitive, social and linguistic aspects that allow different trends of learners of the Portuguese as foreign language. The study is driven based on the primacy of meaning principle when processing input and on the principles of later learning of languages. Data comprise syntactic structures with deviations of nominal agreement written by 10 groups of learners of the Portuguese language in African, Asian and European Universities. Quantitative and qualitative analysis reveals that majority of non-target nominal agreement involves noun phrases used as direct object and complementizer of a preposition and sentences with predicative of the subject. Different trends revealed by groups of Korean and German learners suggest that, among other aspects, word order of each language plays a relevant role for the occurrence of deviations in certain contexts.
\end{abstract}

Keywords: Nominal agreement. Contexts and syntactic functions. African, Asian and European learners of the Portuguese as foreign language. Tendencies.

Recebido em: 09/07/2020 // Aceito em: 26/04/2021. 


\section{Introdução}

As dificuldades que se observam no estabelecimento da concordância nominal $(\mathrm{CN})$ por aprendentes de PLE de diferentes perfis sociolinguísticos (MARIOTTO; LOURENÇOGOMES, 2013; MARTINS, 2015; NHATUVE, 2019; PINTO, 2012) justificam a necessidade de trabalhos descritivos que possam revelar os comportamentos dos diferentes grupos, expor aspectos transversais e particulares e validar os pressupostos teóricos relevantes para cada tendência.

À luz das teorias de processamento da informação - com particular destaque para input processing de VanPatten (2004) - e de contato linguístico (MARTINS, 2008; GASS, 1979), intentamos, com este artigo, identificar os contextos sintáticos em que tendencialmente ocorrem os desvios de $\mathrm{CN}$ e avaliar, sob o ponto de vista da cross-linguistic influence, a relação entre as tendências desviantes de $\mathrm{CN}$ e aspectos relevantes das línguas maternas (LM) dos aprendentes.

A análise de dados à luz das teorias ora selecionadas permite-nos, por um lado, observar aspectos psicolinguísticos que, no âmbito de aprendizagem de PLE, (des)favorecem o desenvolvimento da competência de estabelecer a $\mathrm{CN}$ entre os diferentes elementos de SNs distribuídos em diferentes contextos em que desempenham determinadas funções sintáticas; por outro, permite-nos entender até que ponto o fenômeno de crosslinguistic influence e os subsistemas de memória a longo prazo impactam o processo de harmonização de traços de número e de gênero gramaticais em SNs. Desta feita, será possível desenhar e implementar estratégias que minimizem o impacto dos fatores que desfavorecem o desenvolvimento harmonioso de competências de CN em PLE. 
Nesse contexto, a teoria de processamento do input, de modo particular, o "princípio da primazia do significado", de VanPatten, releva do fato de capitalizar o processamento de material morfológico (HASHEMNEZHAD; ZANGALANI, 2013, p. 24) por aprendentes de línguas não maternas e, consequentemente, acautelar-se, dentre outros aspectos, da explicação de realizações desviantes de CN. Efetivamente, interessam, de forma especial, as hipóteses explicativas de natureza psicocognitivas para a ocorrência de desvios de $\mathrm{CN}$, nomeadamente, (1) a preferência pelo processamento das unidades lexemáticas antes das morfemáticas, (2) a opção pelo tratamento de estruturas menos redundantes e (3) em posição inicial da oração.

Por seu turno, sob o ponto de vista de contato linguístico, sublinhamos o papel das LMs dos diferentes grupos de aprendentes tardios de PLE e dos subsistemas de memórias de longo prazo na aprendizagem do português em geral e dos mecanismos de $\mathrm{CN}$ em particular. Aliás, em situação de contato linguístico, sabe-se que a aprendizagem tardia ocorre depois do chamado "período crítico", em que os mecanismos aquisitivos estão ativos (MADEIRA, 2017, p. 306), resultando em dificuldades acentuadas para desenvolver a mestria linguística, dando lugar a processos compensatórios, tais como a transferência linguística de unidades lexicais, estruturas sintáticas e estratégias de uso da LM para a língua-alvo (GASS, 1979; WEINREICH, 1953). Já no que tange aos sistemas de memória, mostra-se relevante ponderar o papel dos subsistemas de memória a longo prazo procedimental e declarativa (MARTINS, 2016) no estabelecimento da CN por aprendentes de PLE. 
Enquanto o subsistema de memória a longo prazo procedimental se relaciona com os mecanismos implícitos de aprendizagem das línguas, facilitando o desenvolvimento de competências de aspetos fonológicos, morfológicos, sintáticos e semânticos, o subsistema de memória a longo prazo declarativa tem que ver com mecanismos explícitos e permite o desenvolvimento de conhecimento metalinguístico, possibilitando a verbalização do conhecimento que se tem sobre a língua (MARTINS, 2016, 2008; PARADIS, 2008; 2009; 1994).

A amostra integra 315 sintagmas nominais (SN) e frases de predicação de sujeito em que ocorrem desvios de CN. Estas estruturas foram extraídas de um total de 100 textos escritos por 10 grupos de aprendentes de PLE (uma média de 10 textos por cada grupo). A análise destes dados, conduzida com recurso a uma abordagem mista, toma como referência a variedade europeia do português.

\section{0 problema}

Estudos recentes sobre a aquisição/aprendizagem tardia de PLE em diferentes contextos por aprendentes com diferentes perfis sociolinguísticos (MARIOTTO, 2014; MARIOTTO; LOURENÇO-GOMES, 2013; MARTINS, 2015; NHATUVE, 2019; PINTO, 2012; 2017) têm revelado, de forma sistemática, que é na área da $\mathrm{CN}$ que se registra maior índice de dificuldades e lentidão no desenvolvimento de competências em PLE. Ademais, as dificuldades observam-se em quase todos os grupos que aprendem PLE e se traduzem em realizações desviantes de concordância nominal em número (CNN) (NHATUVE; BWETENGA, 2018) e de concordância nominal em gênero (CNG) (FERREIRA, 2013; 2019). 
No entanto, apesar de sabermos que as dificuldades de estabelecer a CNN e a CNG caracterizam a maioria dos aprendentes de PLE, com o intuito de expor com detalhes tais dificuldades com vista a permitir uma intervenção de índole linguístico-pedagógica a favor da aprendizagem e expansão do português no mundo, torna-se necessário identificar e compreender os contextos sintáticos (natureza da estrutura sintática e respectiva função) em que tendencialmente ocorrem os desvios de $\mathrm{CN}$ : será que os desvios ocorrem de forma homogênea em todos os constituintes sintáticos da frase?

Outrossim, havendo uma tendência de as dificuldades de harmonizar os traços gramaticais de número e de gênero em português caracterizarem grupos de perfis sociolinguísticos diferentes, é interessante questionar sobre a sensibilidade dessa área de $\mathrm{CN}$ relativamente ao papel da LM na aprendizagem tardia do português. As questões referentes a esse aspecto procuram respostas sobre quais são os aspectos das LMs que (des) favorecem a simetria ou a assimetria dos contextos sintáticos em que ocorrem os desvios de $\mathrm{CN}$ em estruturas sintáticas escritas por aprendentes de PLE.

Sob o ponto de vista psicocognitivo, em consideração da teoria de processamento de input e, de forma específica, do "princípio da primazia do significado" (VANPATTEN, 2004), podemos avançar, como hipótese à pergunta sobre os constituintes em que ocorrem os desvios de $\mathrm{CN}$, que, apesar de estes poderem registrar-se em todos os contextos em que ocorrem os SNs (sujeito, objeto direto, complemento de preposição), existem contextos que se revelam mais propensos de ocorrência de $\mathrm{CN}$ divergente em relação aos outros. 
Nesse contexto, considerando, por um lado, que os aprendentes de línguas estrangeiras, em geral, tendem a processar preferencialmente o material linguístico (estruturas sintáticas) em posição inicial da frase - princípio de processamento preferencial de elementos na posição inicial da oração (VANPATTEN, 2004) -, observar-se-ão menos desvios de $\mathrm{CN}$ em SN iniciais, com as funções de sujeito, enquanto em sujeitos em posições irregulares (pós-verbais), em SN com funções de objeto direto e em SN subordinados a um sintagma preposicional (SP) (desempenhando várias funções sintáticas), registrar-se-á uma tendência de ocorrência de elevado índice de realizações não convergentes de $\mathrm{CN}$.

Acreditando na onipresença da LM no processo de aquisição/ aprendizagem tardia de uma língua não materna (MADEIRA, 2017), considerando as diferenças das características das LMs selecionadas no que diz respeito à ordem básica das palavras (SVO, SOV e VOS) e no que concerne aos mecanismos de indicação do gênero e do número, achamos que essas diferenças têm implicações na ocorrência de um certo tipo de desvio de CN (gênero e número) em determinados contextos sintáticos. Os grupos dos aprendentes cujas LMs têm a ordem SVO e mecanismos de marcação do gênero e do número mais ou menos semelhantes aos do português apresentarão tendências de desvios de $\mathrm{CN}$ em contextos sintáticos diferentes dos dos aprendentes com línguas de ordem de palavras e mecanismos acentuadamente diferentes dos do português. 


\section{Dados sobre a $\mathrm{CN}$ em português língua não materna}

O conceito de $\mathrm{CN}$ (subtipo de concordância sintática) implica relações de hierarquia e de correspondência de traços gramaticais de número (singular e plural) e de gênero (masculino e feminino, para o caso de português) entre os especificadores e os modificadores (artigos, possessivos, demonstrativos, adjetivos, quantificadores) e os respetivos núcleos nominais no interior do SN ou entre o sujeito e o respetivo predicativo de natureza adjetival ou nominal. Aliás, nesse processo de $\mathrm{CN}$, o nomenúcleo ou expressão equivalente funciona como o controlador (CORBETT, 2003; 2012), isto é, constitui a fonte da qual os elementos subordinados buscam os traços de gênero e número gramaticais da sua variação nesse SN específico.

Para além de ser uma operação de repetição de traços gramaticais, a $\mathrm{CN}$, em línguas em que ocorre, constitui condição indispensável para a gramaticalidade dos enunciados e, ao mesmo tempo, um mecanismo de coesão gramatical dos elementos dentro da frase (PERES; MÓIA, 1995, p. 443). Esse processo, entretanto, ocorre em SNs colocados em diferentes constituintes/contextos frásicos: SN com a função de sujeito, $\mathrm{SN}$ com a função de objeto direto, estruturas de predicação de sujeito e SNs dominados por um SP com diferentes funções sintáticas. Em cada um desses elementos, o SN como tal conserva, como característica própria, a necessidade de harmonização de traços gramaticais de gênero e número entre os elementos acessórios e o núcleo nominal.

Entretanto, o gênero não é uma categoria universal. Existem línguas que têm mecanismos de diferenciação dos gêneros dos nomes (como é o caso do português) e outras que não têm gêneros 
marcados. Existem ainda línguas que só têm dois gêneros (masculino e feminino, no caso de português) e línguas que têm mais de dois gêneros (é o caso do shona, que tem mais de 15 classes/gêneros nominais). Nesse contexto, o mais importante é considerar que as línguas têm o sistema de distinção de gênero se os núcleos dos SNs comandam a concordância, pois "the evidence that nouns have gender in a given language lies in the agreement targets that show gender ${ }^{1}$ ". (CORBETT, 2006a, p. 749).

O fato de a categoria de gênero não ser universal e não existirem critérios comuns, universais e claros para a sua definição e marcação torna a sua aprendizagem e estabelecimento muito complexos. Nesse âmbito, Mota (2016b) alerta que, em oposição à categoria gramatical número (MOTA, 2016a, p. 164 -170), a categoria gramatical de gênero (masculino e feminino), em português, é "inerente", ou seja,

os lexemas nominais [...] têm um valor de gênero inerente, invariável, totalmente especificado na subparte da sua matriz que respeita aos traços morfológicos [...]. Gênero não é, assim, uma categoria flexional, nos nomes; não distingue entre si células de um paradigma nominal, é uma categoria linguística lexical (MOTA, 2016b, p. 152-153).

É considerando a ideia de Mota que alguns autores negam a marcação do valor do gênero através de processos de morfologia flexional (VILLALVA, 1994). Para esses autores, a CN é o único mecanismo morfossintático que revela, sem equívocos, a categoria gramatical de gênero em português (CORBETT, 2006a; LUCCHESI, 2009; RIO-TORTO, 2001).

1 "A evidência de que os nomes têm gênero numa determinada língua reside nos aspectos de concordância que revelam o gênero." (tradução nossa). 
A categoria de número, em oposição à de gênero, revelase presente em todas as línguas, estabelecendo uma relação sólida com a realidade, é motivada (MARTINS, 2015). As noções de pluralidade e de singularidade são universais e a sua representação depende da realidade extralinguística. No caso de português, língua com dois valores de número (o singular e o plural), de uma forma geral, o singular (número não marcado) representa-se por um morfema vazio $(-\varnothing)$, enquanto o plural (número marcado), pelo morfema $-s$ (VILLALVA, 2003, p. 927).

Existe uma expressiva regularidade e sistematicidade dos processos morfológicos de flexão e de marcação dos valores de número (excetuam-se poucos casos como "currículo", corpus...). Essa regularidade é determinante para a facilidade com que os aprendentes de PLE desenvolvem a competência de estabelecer a CNN. Aliás, vários trabalhos sobre a CN em PLE destacam a ocorrência de elevados índices de desvios de CNG se comparados com os de CNN.

Efetivamente, o fato de o gênero em português ser uma categoria inerente ao nome, não sendo, portanto, marcado através de processos morfológicos, associado ao fato de não ser uma categoria com presença e valores uniformes em todas as línguas, tem implicações negativas na aquisição/aprendizagem da CNG em PLE (FERREIRA, 2013; 2019). Em contrapartida, a transparência acentuada dos processos de marcação dos valores de número e a relação sólida desses valores com a realidade favorecem o desenvolvimento de competências de CNN que se registra em vários trabalhos (MARIOTTO; LOURENÇOGOMES, 2013; NHATUVE, 2019; PINTO, 2012). 
No que diz respeito às tendências reveladas na literatura sobre a $\mathrm{CN}$ em português língua não materna, destacam-se, no português falado em Moçambique, Angola e São-Tomé, incongruências de traços gramaticais de gênero e número entre os diferentes especificadores e modificadores e os respetivos núcleos nominais em SNs e frases. No caso do português de Moçambique, os problemas de CN, de acordo com Gonçalves (1997, p. 62-63), são caracterizados pela tendência generalizada do uso de gênero e número não marcados (nos especificadores e modificadores), independentemente dos valores gramaticais do núcleo nominal. Essas dificuldades, na sua generalidade, são explicáveis com base em diferentes fatores sociais e linguísticos.

Essa tendência, entretanto, é oposta ao comportamento dos falantes de português de São-Tomé. Nessa variedade, em conformidade com Miguel e Mendes (2013, p. 151-156), os especificadores e modificadores à esquerda do núcleo nominal projetam o valor gramatical de plural, enquanto os núcleos nominais e os modificadores à direita permanecem no singular. Esse comportamento é igualmente observável no português de Angola, em que ora se flexionam o(s) modificador(es) e especificador(es) antepostos ao núcleo, ora apenas elementos do SN pospostos (INVERNO, 2009, p. 153). Entretanto, à semelhança do português de Moçambique, fatores sociolinguísticos estão na base dessas tendências.

Já sobre o PLE, Pinto (2012; 2017), Nhatuve (2019), Martins (2015), Mariotto e Lourenço-Gomes (2013) revelam os comportamentos de aprendentes africanos (marroquinos e zimbabweanos), asiáticos (chineses) e europeus (espanhóis, ingleses, alemães) de PLE. Nesses estudos, esses autores apresentam as principais dificuldades dos diversos grupos, destacando a área da $\mathrm{CN}$ como uma das mais críticas. 
De acordo com os dados de Pinto (2012), verifica-se a dificuldade em representar o valor de gênero quando o nome em português não pertence às classes temáticas $-o$ ou $-a$ com correlação parcial com o masculino ou o feminino; aliás, para os aprendentes marroquinos, a concordância em gênero mostrase mais difícil de aprender do que a de número (PINTO, 2012, p. 27). Em um outro trabalho, estudando o mesmo grupo de aprendentes de PLE, Pinto (2017) constata que, nos desvios de $\mathrm{CN}$, os aprendentes de PLE apresentam "menor dificuldade de concordância de gênero nos SN complexos do que nos simples", ou seja, os alunos têm mais dificuldades de estabelecer a CN em SNs com a estrutura Det + Nome do que em SNs com a estrutura Det + Nome + Adjetivo (PINTO, 2017, p. 91-110).

Já os dados apresentados por Nhatuve (2019) sobre a CN em PLE de aprendentes zimbabweanos, reiterando a ocorrência de maior número de desvios de $\mathrm{CNG}$ em relação aos de $\mathrm{CNN}$ e a tendência do uso preferencial do gênero e número não marcados (o masculino e o singular), indicam que os desvios envolvem o maior número de núcleos nominais com índice temático (IT) $-a$, e, de uma forma geral, a coincidência dos ITs $-a$ e $-o$ com o feminino e o masculino não é determinante no estabelecimento da CN. Ademais, o estudo de Nhatuve indica que os desvios de $\mathrm{CN}$ ocorrem amiúde em SNs dominados por sintagmas verbais e preposicionais e também em estruturas de predicação de sujeito.

No contexto europeu, Martins (2015) faz uma comparação entre as performances de aprendentes espanhóis, alemães e chineses do PLE na aprendizagem dos aspectos de concordância nos $\mathrm{SNs}$ e em estruturas predicativas e conclui igualmente que a concordância em gênero é sempre "mais difícil do que a $[\mathrm{CN}]$ em número [...] independentemente da LM do aprendente ou, até, do 
seu nível de aprendizagem" (MARTINS, 2015, p. 40-41). Essa tendência, reiterada por Ferreira $(2013 ; 2019)$, fica a dever-se ao fato de o número ser uma categoria semanticamente motivada, com manifestações regulares, enquanto a categoria de gênero se caracteriza por certa assistematicidade. Tal como acontece no português de Moçambique e de outros PALOP, a tendência para o uso generalizado do masculino verifica-se também em aprendentes de PLE europeus (MARIOTTO; LOURENÇOGOMES, 2013, p. 181-183).

Nos casos de aprendentes de PLE, fatores sociais, linguísticos e psicocognitivos concorrem para a ocorrência dos desvios de $\mathrm{CN}$. Ademais, conforme se pode constatar, a maioria dos trabalhos em nosso poder estuda a $\mathrm{CN}$ sob o ponto de vista das tendências na distribuição dos morfemas de concordância no interior do $\mathrm{SN}$, sem identificar, no entanto, os contextos sintáticos (constituintes frásicos) em que ocorre o maior número de desvios.

\section{Metodologia}

A base empírica do nosso trabalho é constituída por 315 estruturas sintáticas (frases e sintagmas) com anomalias de $\mathrm{CN}$. Essas estruturas foram recolhidas através de uma pesquisa documental. Selecionámos textos escritos por aprendentes de PLE (com diferentes níveis de proficiência: A1, A2, B1) sendo falantes de 10 línguas maternas (chinês, alemão, italiano, russo, shona, inglês, coreano, romeno, checo e francês).

Para cada subgrupo selecionámos um mínimo de 10 textos, dos quais identificamos e extraímos $\mathrm{SN}$ e frases que constituem a amostra em análise. Devido ao reduzido número de textos de 
falantes de algumas LM, para evitar uma discrepância acentuada em termos quantitativos, optámos por considerar um mínimo de 24 estruturas sintáticas e um máximo de 35 , isto é, excluímos grupos e textos cuja amostra não perfazia um mínimo de 24 estruturas com desvios de $\mathrm{CN}$.

Os nossos informantes, sendo de ambos os sexos, representam casos de aprendizagem tardia de PLE, em diversas instituições de ensino superior europeias, asiáticas e africanas que, oficialmente, ensinam o português europeu, o que, por sua vez, justifica o recurso a esta variedade como referência na análise dos dados.

Os textos destes aprendentes foram compilados no âmbito de projetos de constituição de corpora de português língua estrangeira e segunda por investigadores do Centro de Linguística da Universidade de Lisboa (CLUL) e do Centro de Estudos de Linguística Geral e Aplicada (CELGA-ILTEC) da Universidade de Coimbra, com exceção dos textos de alunos de LM shona, que foram recolhidos na Universidade do Zimbabwe.

A escolha de um corpus constituído por textos de falantes de 10 LM diferentes fundamenta-se, por um lado, pela necessidade de atestar a transversalidade dos comportamentos dos aprendentes de PLE no estabelecimento da $\mathrm{CN}$ e, por outro, pela necessidade de demonstrar até que ponto as características das LM são (ir)relevantes na ocorrência de tendências desviantes de $\mathrm{CN}$ em determinados contextos sintáticos. A Tabela 1, abaixo, sintetiza as características de cada LM, relevantes para este trabalho: 
Tabela 1: Características das LMs dos informantes

\begin{tabular}{|c|c|c|c|c|c|}
\hline Grupo & F amilia & LM & $\begin{array}{l}\text { Ordem de } \\
\text { palavras }^{1}\end{array}$ & Géneros Gramaticais & $\mathrm{CN}$ \\
\hline \multirow{9}{*}{$\begin{array}{l}\text { Indo- } \\
\text { Europeias }\end{array}$} & \multirow{3}{*}{\begin{tabular}{|l} 
Linguas \\
Românicas \\
\end{tabular}} & Francés & SVO & Masculino Feminino & $\checkmark$ \\
\hline & & Italiano & Svo & Masculino | Feminino & $\checkmark$ \\
\hline & & Romeno & SVO & Masculino / Neutro / Feminino & $\checkmark$ \\
\hline & \multirow[b]{3}{*}{$\begin{array}{l}\text { Linguas } \\
\text { Germânicas }\end{array}$} & & & & \\
\hline & & Inglès & SVO & No & $\mathrm{X}$ \\
\hline & & Alemão & $\begin{array}{l}\text { SVO } \\
\text { SOV } \\
\text { VSO }\end{array}$ & Masculino | Neutro | Feminino & $\checkmark$ \\
\hline & & & & & \\
\hline & \multirow[t]{2}{*}{ Linguas Eslavas } & Checo & SVO $^{3}$ & Masculino | Neutro / Feminino & $\checkmark$ \\
\hline & & Russo & SVO & 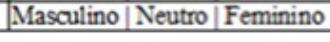 & $\checkmark$ \\
\hline \multirow{3}{*}{$\begin{array}{l}\text { Não Indo- } \\
\text { Europeias }\end{array}$} & Lingua Chinesa & Cantonês & SVO & Nào & $\mathrm{X}$ \\
\hline & \begin{tabular}{|l|} 
Lingua isolada \\
\end{tabular} & Coreano & SOV & Não & $\mathrm{X}$ \\
\hline & Lingua Bantu & Shona & SVO & +15 Classes Nominais & $\checkmark$ \\
\hline
\end{tabular}

Fonte: Elaborado pelo autor.

$\mathrm{O}$ estudo adota as abordagens quantitativa e qualitativa, numa relação de complementaridade. A informação estatística apresentada em tabelas referentes à distribuição das ocorrências desviantes pelas categorias de gênero e número e pelos contextos sintáticos é descrita e discutida tendo em conta, por um lado, os aportes linguísticos e extralinguísticos arrolados na revisão bibliográfica e, por outro, as teorias a que recorremos para esta pesquisa.

\section{Contextos sintáticos e desvios de CN em PLE}

Os dados que analisamos sobre a $\mathrm{CN}$ por aprendentes de PLE revelam, como se pode observar na Tabela 2, a ocorrência de desvios de CNN e CNG em diferentes contextos sintáticos. Efetivamente, existem, de facto, contextos sintáticos propensos à ocorrência de desvios de $\mathrm{CN}$ e outros em que, de uma forma 

em português língua estrangeira

geral, os alunos prestam mais atenção à harmonização de traços gramaticais de gênero e número entre os especificadores, modificadores e os respetivos núcleos nominais em SNs e frases.

\section{Tabela 2 - Distribuição dos desvios de CN pelos contextos e funções sintáticas}

\begin{tabular}{|l|l|l|l|l|l|}
\hline $\begin{array}{l}\text { LM do } \\
\text { aprendente } \\
\text { de PLE }\end{array}$ & $\begin{array}{l}\text { SN- } \\
\text { Sujeito }\end{array}$ & $\begin{array}{l}\text { SN-Objeto } \\
\text { direto }\end{array}$ & $\begin{array}{l}\text { SP - SN com } \\
\text { diferentes } \\
\text { funcões }\end{array}$ & $\begin{array}{l}\text { Frase com } \\
\text { predicativo de } \\
\text { sujeito }\end{array}$ & $\begin{array}{l}\text { Totais em } \\
\text { cada língua }\end{array}$ \\
\hline Chinês & $6(19 \%)$ & $8(26 \%)$ & $8(26 \%)$ & $9(29 \%)$ & $31(100 \%)$ \\
\hline Inglês & $4(14 \%)$ & $7(24 \%)$ & $8(28 \%)$ & $10(34 \%)$ & $29(100 \%)$ \\
\hline Italiano & $4(12 \%)$ & $10(30 \%)$ & $13(40 \%)$ & $6(18 \%)$ & $33(100 \%)$ \\
\hline Shona & $5(14 \%)$ & $10(29 \%)$ & $15(43 \%)$ & $5(14 \%)$ & $35(100 \%)$ \\
\hline Romeno & $1(3 \%)$ & $8(25 \%)$ & $19(59 \%)$ & $4(13 \%)$ & $32(100 \%)$ \\
\hline Russo & $7(22 \%)$ & $12(37 \%)$ & $9(28 \%)$ & $4(13 \%)$ & $32(100 \%)$ \\
\hline Coreano & $12(35 \%)$ & $12(35 \%)$ & $5(15 \%)$ & $5(15 \%)$ & $34(100 \%)$ \\
\hline Alemão & $11(34 \%)$ & $5(16 \%)$ & $9(28 \%)$ & $7(22 \%)$ & $32(100 \%)$ \\
\hline Checo & $4(12 \%)$ & $11(33 \%)$ & $17(52 \%)$ & $1(3 \%)$ & $33(100 \%)$ \\
\hline Francês & $3(12.5 \%)$ & $9(37.5 \%)$ & $3(12.5 \%)$ & $9(37.5 \%)$ & $24(100 \%)$ \\
\hline & $\mathbf{5 7}(\mathbf{1 8 \%} \%)$ & $\mathbf{9 2 ( 2 9 \% )}$ & $\mathbf{1 0 6 ( 3 4 \% )}$ & $\mathbf{6 0}(19 \%)$ & $\mathbf{3 1 5}(\mathbf{1 0 0} \%)$ \\
\hline
\end{tabular}

Fonte: Elaborado pelo autor.

Os dados da Tabela 2 acima revelam que, à parte os grupos de aprendentes de PLE com LM coreana e alemã, os desvios de $\mathrm{CN}$ ocorrem tendencialmente com maior expressão em SNs menos autônomos (dominados por outros elementos), como é o caso do SN-objeto direto (SN-OD) (com um total de 92 (29\%) casos) e do SN complemento de preposição (SP-SN) (com 106 (34\%) casos). Para o caso de grupos de LM chinesa, inglesa e francesa, os desvios concentram-se igualmente em frases com predicativo de sujeito (com 60 (19\%) casos), em que o elemento sujeito à $\mathrm{CN}$ com o núcleo nominal se encontra distante do nome e inserido em um sintagma verbal. É, nesse caso, em contexto de posição inicial da frase, em que o SN com a função de sujeito (com 57 (18\%) casos) registra poucos casos de CN desviante (ver Tabela 2). 
Os princípios de "primazia do significado" bem como a questão de se tratar de aprendizagem tardia de PLE podem explicar parcialmente as tendências de ocorrência de desvios em elementos e posições diferentes do sujeito, em consideração, por um lado, do processamento preferencial dos elementos na posição inicial (VANPATTEN, 2004), daí a ocorrência de baixo índice de desvios em SN-Sujeito, por outro, em consideração das dificuldades próprias do processo de aprendizagem tardia das línguas não maternas (MADEIRA, 2017), que requer esforço e atividades sistemáticas (PEREIRA; MARTINS, 2009, p. 3).

No entanto, nem os princípios da primazia do significado considerados neste estudo nem o fato de se tratar de situações de aprendizagem tardia de PLE conseguem explicar satisfatoriamente a ocorrência de altos índices de desvios de $\mathrm{CN}$ em SN-Sujeitos nos dados de aprendentes de PLE que têm como LM o coreano (língua sem sistema de $\mathrm{CN}$ ) e o alemão (língua com sistema de $\mathrm{CN}$ ). Considerando esses fatos e também os dados da Tabela 1 em geral, parece que nem a questão de umas línguas possuírem mecanismos de marcação de número e de gênero nem o fato de algumas não possuírem mecanismos gramaticais de distinção de gênero são capazes de explicar essa situação.

Entretanto, observando as características das línguas maternas apresentadas na Tabela 1, observamos que o coreano é uma língua de ordem SOV (BYON, 2009, p. 9) e sem mecanismos de distinção dos valores gramaticais de masculino e de feminino, enquanto o alemão, tendo mecanismos de indicação dos dois valores de gênero e também do neutro e muitas formas de marcação do plural (BLOCK, 2013, p. 18-19, 46 ), em termos de ordem de palavras, dependendo dos elementos envolvidos na 
construção de frases, admite várias ordens (SVO, SOV, VSO, OVS) (BLOCK, 2013, p. 88-89; WEBER; MÜULLER, 2004, p. 71-77). Desta feita, parece que a ordem dos constituintes básicos no coreano bem como a possibilidade de várias ordens - que muitas vezes implica o movimento/deslocamento de constituintes básicos - em alemão desempenham um papel relevante para a ocorrência de maior índice de desvios de $\mathrm{CN}$ em SN-Sujeito do português, ${ }^{2}$ cuja ordem básica é SVO.

Cruzando essa explicação com a questão de processamento linguístico (do input) e considerando que, na língua coreana, com a ordem básica SOV, os elementos que ocorrem no final da frase (como, por exemplo, os verbos) são os mais importantes (BYON, 2009, p. 10), pode relacionar-se esse fato com a falta de processamento da $\mathrm{CN}$ em SN-Sujeitos escritos (na posição inicial da frase) por aprendentes de PLE sendo falantes de LM coreana.

Quanto aos desvios de CN no predicativo de sujeito, nomeadamente, nos dados de aprendentes de PLE com LM chinesa, inglesa e francesa, para além do princípio da preferência por estruturas menos redundantes, concorre para a sua explicação a distância entre o predicativo e o nome com que deve concordar.

No que concerne às grandes categorias de $\mathrm{CN}$, observamos que, em todos os 10 grupos falantes de LMs diferentes, se registram baixos índices de desvios de $\mathrm{CNN}$, em comparação com os desvios de CNG. Efetivamente, esse comportamento de aprendentes de PLE revela-se transversal e independe das várias circunstâncias (ação de LM, contexto de aprendizagem) que condicionam o desenvolvimento de competências em PLE. As

\footnotetext{
2 Essa tendência deve ser confirmada ou informada em estudos futuros que se baseiem em dados quantitativos mais representativos, envolvendo falantes de outras LMs com ordens de constituintes sintáticos diferentes da ordem SVO, típica do português.
} 
estruturas sintáticas no Exemplo 1 representam o tipo de desvios de CNN predominante em textos escritos por membros de cada grupo de aprendentes de PLE:

\section{Exemplo 1:}

a. Tenho *[os cabelos longos e claro]. - CHECO.ER.A2.47

- $1.1^{\mathrm{a}}$ ( = os cabelos claros)

b. *[Esta férias] de Natal, eu vou viajar a Lisboa. COREANO.CA.A2.86 - 75.3S (= Estas férias)

c. *[Os maxibombos são um pouco mais confortável] mas caros. - ALEMÃO.ER.A2.99 - 75.3S (= os machimbombos são um pouco mais confortáveis)

d. *[(Nós) Sommos muito feliz]. - ED_1_15_10.1C (= felizes)

e. Muitas vezes moram em * [paìs differentes]. - ITALIANO.

ER.A2.96 - 75.3S (= país diferente)

f. *[São as nossas conversação] - frances.b2.87.69.3q (= São as nossas conversações)

g. [... mundo exterior *d[as oportunidade] BU_2_36_70.3Q (= as oportunidades)

h. Tem *[muito coisas] em madeira - RUSSO.CA.A2.21-1. $1 \mathrm{~A}$ (= muitas coisas)

i. Quando terminar *[a minha exames]. H PII14/15/16SI/ II52 (F985) (= os meus exames)

j. [...] *[vários sitio] da Figueira da Foz (CHINÊS. CA.A2.82-07-265) (= vários sítios)

Os exemplos apresentados em 1 (a. - j.) representam casos de incongruências de traços gramaticais de número entre os especificadores e adjetivos e os respetivos núcleos nominais. 
Conforme se pode observar nos exemplos e na Tabela 3, abaixo, há poucos casos de desvios de CNN no SN-Sujeito. Nesse contexto, pode se considerar que, quanto mais à direita estiver um determinado $\mathrm{SN}$, em relação ao sujeito da frase, maior probabilidade de ocorrência de desvios de $\mathrm{CNN}$ existe. Ademais, confirmando o que tem sido revelado por vários estudos sobre a CNN (MARTINS, 2015; NHATUVE; BWETENGA, 2018), a maioria dos desvios consiste na combinação de especificadores e/ou modificadores com traços de [+ Singular] com núcleos com traços [- Singular] (tendência do uso desviante do singular). A Tabela 3 ilustra a distribuição dos desvios de CNN pelos diferentes contextos sintáticos que consideramos neste trabalho.

\section{Tabela 3 - Distribuição dos desvios de CNN pelos contextos e funções sintáticas}

\begin{tabular}{|l|l|l|l|l|l|}
\hline $\begin{array}{l}\text { LM do } \\
\text { aprendente } \\
\text { dePLE }\end{array}$ & SN-Sujeito & $\begin{array}{l}\text { SN-Objeto } \\
\text { direto }\end{array}$ & $\begin{array}{l}\text { SP - SN com } \\
\text { diferentes } \\
\text { funcões }\end{array}$ & $\begin{array}{l}\text { Frase com } \\
\text { predicativo de } \\
\text { sujeito }\end{array}$ & $\begin{array}{l}\text { Totais em } \\
\text { cada língua }\end{array}$ \\
\hline Chinês & $\mathbf{1}(\mathbf{2 0} \%)$ & $0(0 \%)$ & $0(0 \%)$ & $4(80 \%)$ & $5(100 \%)$ \\
\hline Inglês & $0(0 \%)$ & $1(25 \%)$ & $0(0 \%)$ & $3(75 \%)$ & $4(100 \%)$ \\
\hline Italiano & $0(0 \%)$ & $2(40 \%)$ & $3(60 \%)$ & $0(0 \%)$ & $5(100 \%)$ \\
\hline Shona & $1(20 \%)$ & $0(0 \%)$ & $2(40 \%)$ & $2(40 \%)$ & $5(100 \%)$ \\
\hline Romeno & $0(0 \%)$ & $2(40 \%)$ & $3(60 \%)$ & $0(0 \%)$ & $5(100 \%)$ \\
\hline Russo & $0(0 \%)$ & $3(75 \%)$ & $1(25 \%)$ & $0(0 \%)$ & $4(100 \%)$ \\
\hline Coreano & $1(14 \%)$ & $4(58 \%)$ & $1(14 \%)$ & $1(14 \%)$ & $7(100 \%)$ \\
\hline Alemão & $0(0 \%)$ & $0(0 \%)$ & $0(0 \%)$ & $5(100 \%)$ & $5(100 \%)$ \\
\hline Checo & $1(17 \%)$ & $4(66 \%)$ & $1(17 \%)$ & $0(0 \%)$ & $6(100 \%)$ \\
\hline Francês & $1(25 \%)$ & $2(50 \%)$ & $0(0 \%)$ & $1(25 \%)$ & $4(100 \%)$ \\
\hline & $\mathbf{5 ( 1 0 \% )}$ & $\mathbf{1 8 ( 3 6 \% )}$ & $\mathbf{1 1 ( 2 2} \%)$ & $\mathbf{1 6}(\mathbf{3 2} \%)$ & $\mathbf{5 0}(100 \%)$ \\
\hline
\end{tabular}

Fonte: Elaborado pelo autor.

Os dados da Tabela 2 reiteram conclusões - ocorrência de baixos índices de CNN (Tabela 3) em relação aos de CNG (Tabela 4) - a que chegaram vários autores que estudaram as tendências de $\mathrm{CN}$, quer em grupos de falantes africanos de português língua segunda (GONÇALVES, 1997; INVERNO, 2009), quer em 
grupos de aprendentes africanos de PLE (NHATUVE, 2019; PINTO, 2012; 2017), quer ainda em grupos de aprendentes europeus e asiáticos (MARIOTTO; LOURENÇO-GOMES, 2013; MARTINS, 2015). Conforme se pode depreender, de um total de 315 estruturas sintáticas (ver os totais na Tabela 2), apenas 50 (ver os totais na Tabela 3 ) representam desvios de CNN. No entanto, esses dados opõem-se às tendências observadas no português do Brasil, em que, de uma forma geral, só se relatam sistematicamente casos de desvios de CNN (SCHERRE, 1994; VIEIRA; BRANDÃO, 2014).

As tendências positivas que se registram na aprendizagem e marcação da CNN em PLE requerem uma reflexão profunda se levarmos em conta os princípios teóricos que consideramos neste trabalho. Se, apesar de os nossos informantes representarem, na sua totalidade, casos de aprendizagem tardia do português (MADEIRA, 2017), se a CNN em SN do português é tipicamente uma expressão de redundância de valores gramaticais de número (VANPATTEN, 2004), e mesmo assim os diferentes grupos de aprendentes de PLE revelarem facilidade na aprendizagem dos mecanismos de CNN, então, esse fenômeno (a CNN) representa uma exceção quanto aos princípios das teorias em causa.

Aliás, de acordo com Krashen (1981; 1985), a compreensibilidade e a clareza de input são fatores determinantes para que a aquisição/aprendizagem de uma língua não materna tenha lugar com eficácia. Entretanto, tal como afirma Corbett (2006b), o número, contrariamente ao gênero, é uma categoria universal, e a representação dos valores gramaticais de plural ou de singular depende sobremaneira da realidade (MARTINS, 2015). Ademais, os respetivos mecanismos de flexão e marcação em português revelam altos níveis de sistematicidade 
(VILLALVA, 2003, p. 927). É, em nosso entender, esse quadro teórico que melhor explica os comportamentos dos diferentes grupos de aprendentes de PLE no que tange ao estabelecimento da CNN.

A comparação entre as Tabelas 3 (sobre a distribuição dos desvios de $\mathrm{CNN}$ ) e 4 (referente à distribuição dos desvios de $\mathrm{CNG}$ ) permite-nos constatar que, em todos os contextos e funções sintáticas considerados e em todos os grupos de aprendentes de PLE, os índices elevados de desvios dizem respeito à $\mathrm{CNG}$. $\mathrm{O}$ Exemplo 2 a seguir, com itens extraídos de cada grupo, ilustra a natureza de estruturas desviantes predominantes em diferentes níveis de proficiência.

\section{Exemplo 2:}

a. Tendo *[os relações] superfíceis com elas. - CHECO. ER.B1.32 - 77.3T - (= as relações)

b. *[Meus amigas] falam a mim. - COREANO.CA.A2.26

$-1.1^{\mathrm{a}}-(=$ As minhas amigas $)$

c. ${ }^{*}[$ O nosso vida] de país tomava fim - ALEMÃO. CA.A2.20 1. $1^{\mathrm{a}}-(=$ a nossa vida $)$

d. Jogar jogos *n[a minha computador] portátil. INGLÊS.CF.A2.03 33.1J - (= no meu computador)

e. Vou falar *d[os diferentes paisagens] - PA_1_07_75.3S - (= das diferentes paisagens)

f. *[O ambiente dessa cidade é muito parecida] - frances. b2.87.69.3q $-(=\mathrm{o}$ ambiente [...] parecido $)$

g. Eu moro*[ em o cidade] chamado Oradea - ROMENO. ER.A2.72 - $1.1^{\mathrm{a}}-(=$ na cidade $)$

h. *[Éste refeição e muito gordo] - RUSSO.CA.B1.53 $55.2 \mathrm{M}$ - (= Esta refeição [...] gorda) 
i. [...] comprar $*$ [muitos coisas]: camisa, sapatos, comidas etc (CHINÊS(CANTONÊS). CF.A2.08-02-34) (= muitas coisas)

j. Querei *[muitas bom comidas]. PII14/15/16SI/II52 (F987) (= muito boa comida)

As estruturas sintáticas em 2 (a. - j.) representam os desvios de $\mathrm{CNG}$ encontrados em textos escritos pelos 10 grupos de aprendentes de PLE. Esses exemplos indicam, tal como revelam as estatísticas na Tabela 4, poucos casos de desvios de CNG em SN-Sujeito, com a excepção dos casos dos aprendentes de LM coreana e alemão, que apresentam elevados índices de desvios em SN com essa função sintática. Os desvios registrados, na sua maioria, consistem na combinação de especificadores e modificadores com traços gramaticais [+ Masculino] com núcleos nominais [- Masculino] (tendência do uso desviante do masculino). Embora esse comportamento se registre também em alguns $\mathrm{SNs}$ com núcleos pertencentes às classes temáticas $-a \mathrm{e}$ - o, os índices elevados de desvios envolvem $\mathrm{SN}$ com núcleos que não integram essas duas classes (ver os núcleos de $\mathrm{SN}$ em Exemplo 2 (a., d., e., f., g., e h.) (FERREIRA, 2013; 2019; NHATUVE, 2019), sobre as tendências de marcação de gênero gramatical em PLE). A Tabela 4, a seguir, ilustra a distribuição dos desvios de CNG pelos contextos sintáticos: 
Contextos sintáticos e desvios de concordância nominal em português língua estrangeira

Tabela 4 - Distribuição dos desvios de CNG pelos contextos e funções sintáticas

\begin{tabular}{|l|l|l|l|l|l|}
\hline $\begin{array}{l}\text { LM do } \\
\text { aprendente } \\
\text { dePLE }\end{array}$ & SN-Sujeito & $\begin{array}{l}\text { SN-Objeto } \\
\text { direto }\end{array}$ & $\begin{array}{l}\text { SP - SN com } \\
\text { diferentes } \\
\text { funções }\end{array}$ & $\begin{array}{l}\text { Frase com } \\
\text { predicativo de } \\
\text { sujeito }\end{array}$ & $\begin{array}{l}\text { Totais em } \\
\text { cada língua }\end{array}$ \\
\hline Chinês & $\mathbf{5 ( 1 9 \% )}$ & $8(31 \%)$ & $8(31 \%)$ & $5(19 \%)$ & $26(100 \%)$ \\
\hline Inglês & $4(16 \%)$ & $6(24 \%)$ & $8(32 \%)$ & $7(28 \%)$ & $25(100 \%)$ \\
\hline Italiano & $4(14 \%)$ & $8(29 \%)$ & $10(36 \%)$ & $6(21 \%)$ & $28(100 \%)$ \\
\hline Shona & $4(14 \%)$ & $10(33 \%)$ & $13(43 \%)$ & $3(10 \%)$ & $30(100 \%)$ \\
\hline Romeno & $1(4 \%)$ & $6(22 \%)$ & $16(59 \%)$ & $4(15 \%)$ & $27(100 \%)$ \\
\hline Russo & $7(25 \%)$ & $9(32 \%)$ & $8(28 \%)$ & $4(14 \%)$ & $28(100 \%)$ \\
\hline Coreano & $11(41 \%)$ & $8(29 \%)$ & $4(15 \%)$ & $4(15 \%)$ & $27(100 \%)$ \\
\hline Alemão & $11(41)$ & $5(19 \%)$ & $9(33 \%)$ & $2(7 \%)$ & $27(100 \%)$ \\
\hline Checo & $3(11 \%)$ & $7(26 \%)$ & $16(59 \%)$ & $1(4 \%)$ & $27(100 \%)$ \\
\hline Francês & $2(10 \%)$ & $7(35 \%)$ & $3(15 \%)$ & $8(40 \%)$ & $20(100 \%)$ \\
\hline & $\mathbf{5 2 ( 2 0 \% )}$ & $\mathbf{7 4 ( 2 8 \% )}$ & $\mathbf{9 5 ( 3 6 \% )}$ & $\mathbf{4 4 ( 1 6 \% )}$ & $\mathbf{2 6 5}(100 \%)$ \\
\hline
\end{tabular}

Fonte: Elaborado pelo autor.

Em termos da distribuição dos desvios de CNG, a Tabela 4 (e também a Tabela 3) reproduz os comportamentos dos diferentes grupos de aprendentes de PLE observados na Tabela 2. A descrição dos dados dessa tabela reitera a ocorrência de baixos índices de desvios em SN-Sujeito (com 52 (20\%) casos), contra os totais de $74(28 \%)$ e $95(36 \%)$ casos de desvios em SN-OD e em SP-SN, respetivamente. A ocorrência de maior número de desvios de CNG que se confirma com os dados da Tabela 4 em comparação com os da Tabela 3 (sobre a $\mathrm{CNN}$ ) é um dado que se observou em todos os estudos feitos sobre a $\mathrm{CN}$ em português língua não materna (GONÇALVES, 1997; MARTINS, 2015; NHATUVE, 2019; PINTO, 2012; 2017). A mais valia deste estudo, no que se refere estritamente a esse aspecto, reside no fato de confirmar essa tendência através da comparação de dados de diferentes grupos de aprendentes de PLE.

Enquanto os dados sobre a CNN não nos permitiram explicar e/ou relacionar satisfatoriamente a ocorrência de baixos índices de desvios com base nas dificuldades inerentes 
à aprendizagem tardia do português (MADEIRA, 2017) bem como nos princípios da não redundância (VANPATTEN, 2004), a superioridade numérica dos dados referentes aos desvios de CNG permite a sua explicação com base nesses aspectos. A dificuldade de estabelecer a CNG pode ser explicada também pelo fato de os aprendentes tardios não se beneficiarem da memória a longo prazo procedimental, que facilitaria a aquisição de competências de CNG. De fato, esses grupos recorrem à memória a longo prazo declarativa para a aprendizagem, o que requer muito "esforço e atenção deliberada, mediante repetição e o necessário tempo de assimilação" (PEREIRA; MARTINS, 2009, p. 32-33).

Por seu turno, se a harmonização dos valores gramaticais de gênero entre os especificadores e modificadores e os respetivos núcleos é um processo redundante, então a preferência pela não redundância, que, segundo VanPatten (2004), caracteriza aprendentes de línguas estrangeiras, concorre como fator explicativo das tendências desviantes de CNG. Mais ainda, se a esmagadora maioria de casos representa a tendência de uso desviante do masculino, em que apenas os núcleos nominais é que evidenciam o valor de gênero feminino, enquanto os especificadores e modificadores permanecem na forma não marcada, então, o princípio da preferência pelo processamento de palavras lexemáticas em detrimento das morfemáticas também pode ser aplicado como fator explicativo dos desvios de CNG.

Aliás, o gênero gramatical não é uma categoria universal. Os respetivos mecanismos de expressão/marcaçãonão são fidedignos nem são sistemáticos (CORBETT, 2006a; 2016b; VILLALVA, 1994; MOTA, 2016a; MARTINS, 2015; FERREIRA, 2019). Ademais, as línguas com sistemas de CNG não recorrem a 
estratégias semelhantes para a expressão do gênero, o que torna o respetivo input menos claro e menos compreensível (KRASHEN, 1982; 1985). Estes fatos, entretanto, desfavorecem o desenvolvimento de competências de estabelecimento de CNG em PLE.

\section{Considerações finais}

Neste trabalho, analisámos, à luz das teorias de processamento do input e de contato linguístico, o comportamento de 10 grupos de aprendentes de PLE com LMs diferentes no estabelecimento da $\mathrm{CN}$. Concentrámos as nossas atenções na distribuição das realizações desviantes de $\mathrm{CN}$, com o objetivo de observar, tal como anunciámos na introdução, quais os contextos sintáticos (posição do SN na frase e a respetiva função sintática) em que tendencialmente ocorrem com maior expressão os desvios de $\mathrm{CN}$ e quais os aspectos teóricos de natureza psicocognitiva, social e linguística que favorecem e/ou explicam os comportamentos dos 10 grupos de aprendentes de PLE.

As amostras de cada grupo de aprendentes, em consonância com outros estudos (FERREIRA, 2019; MARTINS, 2015; NHATUVE, 2019; PINTO, 2017), indicam, de facto, que a dificuldade de estabelecer a $\mathrm{CN}$ caracteriza quase todos os aprendentes de PLE e que a CNG é a que implica elevados índices de realizações à margem da norma do português europeu, ou seja, é na CNG que se registra a maior parte de casos de incongruência de traços gramaticais de gênero entre os especificadores e modificadores e os respetivos núcleos nominais. Aliás, os dados que apresentamos nas Tabelas 3 e 4 permitem-nos observar que, das 315 (100\%) estruturas sintáticas 
registradas, $265(84 \%)$ correspondem aos desvisos de CNG, contra $50(16 \%)$ que representam desvios de CNN. Ademais, as estruturas sintáticas estudadas confirmam as tendências para o uso desviante e preferencial do número singular (ver Exemplo 1: a. - j.) e do gênero masculino (ver Exemplo 2: a. - j.) nos especificadores e modificadores.

Entretanto, no que diz respeito ao contexto sintático em que ocorrem os desvios de $\mathrm{CN}$, quer os dados referentes à distribuição dos desvios de CNN pelos diferentes contextos considerados neste trabalho (ver Tabela 3), quer os dados sobre a distribuição dos desvios de CNG (ver Tabela 4), ambos convergem, de uma forma geral, com os dados gerais apresentados na Tabela 2, no que tange ao comportamento dos diferentes grupos de aprendentes de PLE. Em conformidade com as estatísticas das três tabelas, os índices elevados de desvios de $\mathrm{CN}$ ocorrem em SN-OD, em SP-SN e também em estruturas de predicação do sujeito. Portanto, registram-se poucos desvios de $\mathrm{CN}$ em $\mathrm{SN}$ que ocupam as posições iniciais da frase e com as funções de sujeito da frase.

A ocorrência de baixos índices de desvios em SNSujeito, em oposição às tendências em SN-OD e em SP-SN, valida, em geral, o princípio de processamento preferencial de estruturas sintáticas (neste caso, SN) na posição inicial da frase (VANPATTEN, 2004). No entanto, embora a maioria dos dados estudados revele essa tendência, há dois grupos (de aprendentes de LM coreana e alemã) que apresentam tendências diferentes. Nas amostras desses dois grupos, observámos que é no SN-Sujeito que se concentram os desvios (ver Tabelas 2 e 4). Parece que nem os princípios de primazia do significado nem a questão de se tratar de aprendizagem tardia de PLE 
explicam satisfatoriamente por que são esses dois grupos que se comportam de maneira particular no que tange ao contexto em que ocorrem os desvios de $\mathrm{CN}$.

Nesse contexto, na tentativa de entendermos o que provavelmente está na base da ocorrência de índices elevados de desvios de CN em SN-Sujeito em aprendentes com LM coreana, com 12 casos correspondentes a 35\%, e em aprendentes com LM alemã, com 11 casos que representam 34\%, verificámos que o coreano é uma língua de ordem SOV (BYON, 2009, p. 9), enquanto, embora se observe no alemão a ordem SVO, essa língua também admite as ordens SOV, VSO, OVS (BLOCK, 2013; WEBER; MÜULLER, 2004), dependendo, dentre outros aspectos, da natureza dos elementos envolvidos na frase. Assim, pode se relacionar a ocorrência de altos índices de desvios com a falta de processamento da $\mathrm{CN}$ em SN-Sujeito em escritos de aprendentes de PLE, sendo falantes das duas LMs. É, em nosso entender, nas características das LMs que se encontra a explicação do fato de os aprendentes de PLE com LM coreana e alemã apresentarem elevados índices de desvios em SN-Sujeito.

Outrossim, se os princípios da primazia do significado e do contato linguístico preveem dificuldades acentuadas explicáveis com base nas tendências dos aprendentes de PLE de processarem elementos linguísticos com significado lexical, menos redundantes, e com base no fato de se tratar de uma aprendizagem tardia, a CNN em PLE parece constituir uma exceção, se considerarmos que há uma significativa facilidade na aprendizagem e no desenvolvimento de competências de CNN. Aliás, o sucesso no estabelecimento de CNN explica-se satisfatorimente pelo caráter universal dos valores gramaticais de singular e plural, pela sua estreita relação com a realidade e 
pelo fato de a sua marcação consistir em processos morfológicos altamente regulares (MARTINS, 2015; VILLALVA, 1994).

Em contrapartida, concorrem todos os princípios de primazia do significado e de contato linguístico considerados na revisão bibliográfica para a explicação dos desvios de CNG. Ademais, o fato de o gênero ser uma categoria cuja definição e marcação consistem em critérios e estratégias diferentes e o fato de, em português, a variação em gênero não consistir em processos flexionais (MARTINS, 2015; MOTA, 2016a; 2016b; VILLALVA, 1994) parecem explicar igualmente as dificuldades acentuadas de estabelecer a CNG que se registram.

Portanto, com base neste estudo, observámos que os desvios de $\mathrm{CN}$, na maioria dos casos, ocorrem em posições e em SNs diferentes de sujeito. Ademais, foi possível observar que os grupos de aprendentes de PLE cujas LMs têm ordens de palavras diferentes de SVO, que é típica do português, tendem a apresentar comportamentos diferentes (elevados índices de desvios em SNSujeito). É caso para considerar que a ordem das palavras nas LMs desempenha, em alguns casos, um papel determinante na ocorrência de desvios em determinados contextos sintáticos.

A ocorrência de maior número de desvios em posições diferentes das de sujeito que se observou neste trabalho valida as hipóteses que apresentámos na descrição do problema e confirma, com base em dados mais abrangentes (10 grupos), as conclusões parciais a que chegou Nhatuve (2019), em um estudo da CN em PLE de falantes de LM shona. 


\section{Referências}

BLOCK, R. German grammar in English for international students. München: University of Applied Sciences, 2013.

BYON, A. Basic Korean: a grammar and workbook. New York: Routledge, 2009.

CORBETT, G. Agreement, the range of the phenomenon and the principles of the Surry database of agreement. Transcriptions of the philosophical society, [s. l.], v. 101, n. 2, p. 155-202, 2003. Disponível em: <https://doi.org/10.1111/1467-968X.00117>. Acesso em: 6 jul. 2020.

CORBETT, G. Grammatical gender. In: BROWN, K. (ed.). Encyclopedia of language and Linguisics. 2. ed. Oxford: Elsevier, 2006a. v. 4, p. 749-756.

CORBETT, G. Number. In: BROWN, K. (ed.). Encyclopedia of language and Linguisics. 2. ed. Oxford: Elsevier, 2006b. v. 4, p. 724-731.

CORBETT, G. Grammatical relations in a typology of agreement systems. In: ARGUMENT structure and grammatical relations: a crosslinguistic typology. Studies in language companion series, 126, XV. Amsterdam: John Benjamins Publishing Company, 2012. p. 37-54.

DUARTE, I. Língua portuguesa: instrumento de análise. Lisboa: Universidade Aberta, 2000.

FERREIRA, T. S. A marcação de gênero nominal em português língua não-materna: padrões na aquisição/aprendizagem. In: CARAPINHA, C.; SANTOS, I. A. (coord.). Estudos de Linguística. Coimbra: Imprensa da Universidade de Coimbra, 2013. v. II, p. 77-92.

FERREIRA, T. S. Aquisição/Aprendizagem do sistema de atribuição do gênero nominal em PLNM. 2019. 351 f. Tese 
(Doutorado em Linguística do Português) - Universidade de Coimbra, Coimbra, 2019.

GASS, S. M. Language transfer and universal grammatical relations. Language Learning, [s. l.], v. 29, n. 2, p. 327-344, 1979. Disponívelem: $<$ https://doi.org/10.1111/j.1467-1770.1979. tb01073.x>. Acesso em: 6 jul. 2020

GASS, M.; SELINKER, L. Second language acquisition: an introductory cours. New York and London: Routledge, 2008.

GONÇALVES, P. Tipologia de 'erros' do português oral de Maputo: um primeiro diagnóstico. In: STROUD, C.; GONÇALVES, P. (org.). Panorama do português oral de Maputo. Maputo: Instituto Nacional do Desenvolvimento da Educação, 1997. v. II: A construção de um banco de "erros", p. 37-67.

HASHEMNEZHAD, H.; ZANGALANI, S. K. Input processing and processing instruction: definitions and issues. International Journal of Applied Linguistics \& English Literature, [s. l.], v. 2, n. 1, p. 23-28, 2013.

INVERNO, L. Contact-induced restructuring of Portuguese morphosyntax in interior Angola: evidence from Dundo (Lunda Norte). 2009. 474 f. Tese (Doutoramento em Linguística Portuguesa) - Universidade de Coimbra, Coimbra, 2009.

KRASHEN, S. Second language acquisition and second language learning. New York: Pergamon Press, 1981.

KRASHEN, S. The input hypothesis: issues and implications. UK: Longman, 1985.

KRASHEN, S. Second language acquisition: theory, applications and some conjectures. Cambridge: Cambridge University Press, 2013.

LUCCHESI, D. A concordância de gênero. In: LUCCHESI, D.; BAXTER, A.; RIBEIRO, I. (org.). O português afro-brasileiro. Salvador: EDUFBA, 2009. p. 295-318. 
MADEIRA, A. Aquisição de língua não materna. In: FREITAS, M. J.; SANTOS, A. L. (ed.). Aquisição de língua materna e não materna: questões gerais e dados do português. Berlin: Language Science Press, 2017. p. 305-330. (Textbooks in Language Sciences, 3).

MARIOTTO, E. M. C. Processamento da concordância de género por aprendentes de português como língua estrangeira: evidências de um estudo de leitura automonitorada. 2014. 99 f. Dissertação (Mestrado em Língua e Cultura Portuguesa) Universidade de Lisboa, Lisboa, 2014.

MARIOTTO, E.; LOURENÇO-GOMES, M. C. Análise de erros na escrita relacionados à aprendizagem da concordância de gênero por falantes nativos do inglês, aprendentes de português europeu como língua estrangeira. In: SIMPÓSIO MUNDIAL DE ESTUDOS DE LÍNGUA PORTUGUESA (SIMELP), Língua portuguesa: ultrapassando fronteiras, unindo culturas, 4., 2013, Goiânia. Anais... Goiânia: Faculdade de Letras/UFG, 2013. p. 1.278-1.285.

MARTINS, C. Línguas em contacto. Coimbra: Imprensa da Universidade de Coimbra, 2008. Disponível em: $<$ http://dx.doi. org/10.14195/978-989-26-0433-6>. Acesso em: 30 jun. 2020.

MARTINS, C. Número e gênero nominais no desenvolvimento das interlínguas de aprendentes do português europeu como língua estrangeira. Revista Científica da UEM: Série Letras e Ciências Sociais, [s. l.], v. 1, n. 1, p. 26-51, 2015.

MARTINS, C. O papel diferenciado de subsistemas de memória de longo prazo nos processos de aquisicão e de aprendizagem de uma L2: o modelo declarativo/procedimental e as suas consequências para o ensino de línguas não maternas. In: CORREA-CARDOSO, J.; FIALHO, M. C. (org.). A linguagem na pólis. Coimbra: Imprensa da Universidade de Coimbra, 2016. p. 99-120. Disponível em: <https://doi.org/10.14195/978989-26-1115-0_4>. Acesso em: 30 jul. 2020. 
MIGUEL, M.; MENDES, A. Syntactic and semantic issues in sequences of the type (adjective)-noun-(adjective). Journal of Portuguese Linguistics, [s. l.], v. 12, n. 2, p. 151-156, 2013.

MOTA, M. A. A categoria gramatical gênero, nos nomes e adjetivos do Português: algumas reflexões. Diadorim, Especial, Rio de Janeiro, p. 150-164, 2016 a.

MOTA, M. A. Morfologia nas interfaces. In: MARTINS, A. M.; CARRILHO, E. (ed.). Manual de Linguística Portuguesa. Berlin/Boston: De Gruyter, 2016b. p. 156-177.

NHATUVE, D. Aspectos de concordância nominial em português língua estrangeira por falantes de língua materna Bantu (Shona) e de Inglês língua segunda. 2019. 376 f. Tese (Doutoramento em Linguística do Português) - Universidade de Coimbra, Coimbra, 2019.

NHATUVE, D.; BWETENGA, T. R. Configuração do valor de número gramatical em português língua estrangeira: interlíngua ou problemas intrínsecos da língua portuguesa?. Linguagem \& Ensino, Pelotas, v. 21, n. 1, p. 5-33, 2018. Disponível em: $<$ http://dx.doi.org/10. 15210/rle.v21i1.15152>. Acesso em: 6 jul. 2020.

PEREIRA, I.; MARTINS, C. Metodologias de ensino de PLS à medida dos aprendentes. In: MATEUS, M. H. M. et al. (org.). Metodologias e materiais para o ensino do português como língua não materna. Lisboa: ILTEC, 2009. p. 31-37.

PERES, J.; MÓIA, T. Áreas críticas da língua português. Lisboa: Caminho, 1995.

PINTO, J. A aquisição de português LE por alunos marroquinos: dificuldades interlinguísticas. In: CONGRESO INTERNACIONAL SEEPLU, Difundir la lusofonia, 2., Cáceres, 2012. Atas. Cáceres: SEEPLU/CILEM/LEPOLL, 2012. p. 217239.

PINTO, J. A aquisição do gênero e da concordância de gênero 
em português língua terceira ou língua adicional. In: OSÓRIO, P. (coord.). Teorias e usos linguísticos. Lisboa: Lidel, 2017. p. 91-110.

RIO-TORTO, G. Classes gramaticais: sua importância para o ensino da morfossintaxe. Máthesis, [s. l.], v. 10, p. 259-286, 2001.

SCHERRE, M. M. P. Aspectos da concordância de número no português do Brasil. Revista Internacional de Língua Portuguesa (RILP) - Norma e variação do português, [s.l.], p. 37-49, 1994.

VANPATTEN, B. Processing instruction: theory, research, and commentary. Mahwah, New Jersey: Lawrence Erlbaum Associates, 2004.

VIEIRA, S. R.; BRANDÃO, S. F. Tipologia de regras linguísticas e estatuto das variedades/línguas: a concordância em português. Linguística, [s. l.], v. 30, p. 82-112, 2014.

VILLALVA, A. Estruturas morfológicas: unidades e hierarquias nas palavras de português. Lisboa: Fundação Calouste Gulbenkian, 1994.

VILLALVA, A. Estruturas morfológicas básicas. In: MATEUS et al. Gramática da língua portuguesa. Lisboa: Caminho, 2003. p. 917-978.

WEBER, A.; MÜULLER, K. Word order variation in German main clauses: a corpus analysis. In: INTERNATIONAL CONFERENCE ON COMPUTATIONAL LINGUISTICS, 20., Geneva, 2004. Proceedings. Geneva, Switzerland, 2004. p. 7177.

WEINREICH, U. Languages in contact. Findings and problems (Publications of the Linguistic Circle of New York 1). New York: Linguistic Circle of New York, 1953. 